\title{
Desenvolvimento vegetativo de porta-enxertos de citros produzidos em diferentes recipientes
}

\author{
Vegetative development of citric rootstocks produced in different containers
}

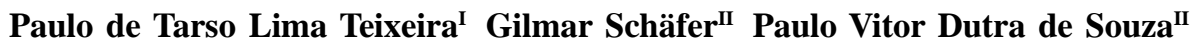 \\ Abel Todeschini ${ }^{\text {II }}$
}

RESUMO

O objetivo deste trabalho foi avaliar o desenvolvimento vegetativo de diferentes porta-enxertos cítricos semeados em bandejas de isopor, em comparação com a semeadura em tubetes cônicos irrigados por capilaridade. $O$ delineamento experimental foi em blocos casualizados, e os tratamentos foram dispostos em parcelas subdivididas, testando os dois tipos de recipientes na parcela principal (tubetes e bandejas de isopor), com volume de substrato de $120 \mathrm{~cm}^{3}$, e nas subparcelas três variedades de porta-enxertos cítricos ('Trifoliata' - Poncirus trifoliata [L.] Raf., citrangeiro 'FEPAGRO C37' - Poncirus trifoliata (L.) Raf. x Citrus sinensis (L.) Osbeck. e tangerineira 'Sunki' - C. sunki hort. ex Tan.). Foram utilizadas 20 plantas por subparcela e três repetições. $O$ desenvolvimento vegetativo, 150 dias após a semeadura, foi superior, de modo geral, nas plantas cultivadas em bandejas. Ao longo do tempo, os porta-enxertos 'FEPAGRO C37' $e$ 'Trifoliata' apresentaram crescimento em altura semelhante entre si e ambos foram superiores à tangerineira 'Sunki'. $O$ citrangeiro 'FEPAGRO C37' foi superior aos demais portaenxertos em relação ao diâmetro e acúmulo de massa seca.

Palavras-chave: Propagação, citrus, tubetes, bandejas, ambiente protegido.

\section{ABSTRACT}

This work aimed to compare the vegetative development of citric rootstocks sowed in isoprene trays on in stiff plastic tubes irrigated by capillarity. The experimental design was a randomized blocks with split plot scheme, testing both containers at the plot (tubes and isoprene trays) with $120 \mathrm{~cm}^{3}$ of substrate volume, and, in the subplot, three citric rootstock varieties (trifoliate orange - Poncirus trifoliata [L.] Raf.), citrange FEPAGRO 'C37' - Poncirus trifoliata (L.) Raf. $x$ Citrus sinensis (L.) Osbeck.] and tangerine 'Sunki' - C. sunki hort. ex Tan.). Twenty plant per subplot were used and three replications. After 150 days of sowing, plants cultivated in trays showed higher vegetative development. Rootstocks FEPAGRO 'C37' and trifoliate orange presented similar height growth and both were higher than tangerine 'Sunki'. Citrange FEPAGRO 'C37' showed longer diameter and dry mass accumulation in relation to other rootstocks.

Key words: propagation, citrus, stiff plastic tubes, isoprene trays, protected environment.

\section{INTRODUÇÃO}

O sistema de produção de mudas cítricas em ambiente protegido consiste na semeadura dos porta-enxertos em bandejas ou tubetes e, posteriormente, a transferência destes para vasos ou sacolas plásticas, com substrato isento de patógenos e em telados à prova de vetores. Isso possibilita a obtenção de mudas em menor tempo, com um sistema radicial mais abundante e desenvolvido, além de facilitar a produção de mudas livres de patógenos (SCIVITTARO et al., 2004).

Alguns produtores têm utilizado bandejas, já outros preferem tubetes na fase de sementeira, em ambiente protegido, ambos obtendo bons resultados. Porém, a utilização de recipientes coletivos, como no caso de bandejas de isopor, permite aos produtores um melhor aproveitamento da área destinada à produção de mudas, além de maior facilidade no manuseio e um menor custo em relação aos recipientes individuais, como os tubetes.

IUniversidade Federal do Rio Grande do Sul (UFRGS). Av. Bento Gonçalves, 7712, Bairro Agronomia, 91540-000, Porto Alegre, RS, Brasil. E-mail: plima37@yahoo.com.br. Autor para correspondência.

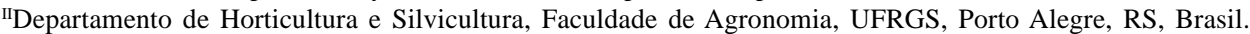


Na fase de sementeira, quando se utilizam recipientes com menor volume, emprega-se o método de irrigação por microaspersão e, no caso específico do cultivo de porta-enxertos cítricos em tubetes ou bandejas, o molhamento da parte área da planta pode facilitar o estabelecimento de doenças fúngicas e bacterianas que são disseminadas pela água (SCHÄFER, 2004). O sistema floating, sistema que se baseia na subirrigação por capilaridade, pode ser classificado como um sistema de fluxo e refluxo. Esse sistema foi testado e mostrou-se eficiente na fase de sementeira, permitindo ganhos em altura de plantas de até 64\% e de 66,7\% para área foliar, obtendo melhorias no aspecto fitossanitário das plantas e permitindo a aplicação de fertilizantes via água de irrigação (SCHÄFER, 2004). Nesse caso, o uso de bandejas alveoladas pode facilitar o processo, dispensando o uso de mesas e facilitando o manejo do sistema

Outras variáveis importantes a serem levadas em consideração são o tamanho e o formato dos recipientes utilizados para formação de mudas frutíferas, pois isso acarreta alterações na quantidade de substrato a ser utilizada, na disponibilidade de nutrientes e água para as plantas, na aeração e em outras variáveis ligadas à estrutura e mão-de-obra disponível no viveiro (BAILEY et al., 2005).

Alterações no volume e formato do recipiente podem alterar a porosidade total, que influencia a retenção de água e a aeração, determinando um crescimento diferenciado das plantas. Além disso, o reduzido volume dos recipientes impõe restrições ao desenvolvimento radicial das mudas, pois, se mantidas por excessivo tempo nos recipientes, apresentarão deformações nas raízes, o que resultará, após o plantio, em diminuição na velocidade de desenvolvimento radicial e da parte aérea das plantas (LEAL et al., 2005).

O objetivo deste trabalho foi avaliar o desenvolvimento vegetativo de plantas de diferentes porta-enxertos cítricos semeadas em bandejas de isopor e tubetes cônicos sob sistema de irrigação por capilaridade.

\section{MATERIAL E MÉTODOS}

O experimento foi conduzido em casa de vegetação, na Estação Experimental Agronômica da Universidade Federal do Rio Grande do Sul (EEA/ UFRGS), situada na Rodovia BR 290 (Km 146), em Eldorado do Sul, Rio Grande do Sul (RS). Foi utilizado o delineamento experimental de blocos casualizados com tratamentos dispostos em parcelas subdivididas, sendo testados dois tipos de recipientes na parcela principal e três porta-enxertos nas subparcelas. Foram utilizadas 20 plantas por parcela e três repetições.
Os recipientes testados foram: bandejas de poliestireno (isopor) contendo 72 células, em formato de troncos de pirâmides invertidas com altura de $120 \mathrm{~mm}$, $50 \mathrm{~mm}$ de lado e $9 \mathrm{~mm}$ de abertura na parte inferior e com volume útil de $120 \mathrm{~cm}^{3}$; e tubetes cônicos de polietileno preto, com $140 \mathrm{~mm}$ de altura, $12 \mathrm{~mm}$ de abertura na parte superior e volume de $120 \mathrm{~cm}^{3}$. Estes continham estrias longitudinais internas e eqüidistantes. Ambos os recipientes possuíam aberturas na parte basal para permitir a drenagem e poda natural das raízes.

Os três porta-enxertos cítricos testados foram: 'Trifoliata' (Poncirus trifoliata [L.] Raf.); citrangeiro 'FEPAGRO C37'(Poncirus trifoliata [L.] Raf. x Citrus sinensis [L.] Osbeck.) e a tangerineira 'Sunki' (C. sunki hort. ex Tan.). Foi utilizado o substrato Plantmax Hortaliças HT, fabricante Eucatex ${ }^{\circledR}$ (composto de cascas processadas e enriquecidas, vermiculita expandida, turfa processada, corretivo da acidez, superfosfato simples e nitrato de potássio), apresentando $\mathrm{pH}$ (em água) de 5,8 (+/-0,5), densidade de $480 \mathrm{~kg} \mathrm{~m}^{-3}$ e CE $1,5 \mathrm{mS} \mathrm{cm}^{-1}(+/-0,3)$. Os dados foram fornecidos pelo fabricante.

Foram utilizadas sementes das plantas cultivadas na coleção de citros da EEA/UFRGS. A metodologia adotada para a extração das sementes é a descrita por (KOLLER, 2006). Essas sementes permaneceram na geladeira $\left(4\right.$ a $6^{\circ} \mathrm{C}$ ), dentro de sacos plásticos com fungicida Captan, até o momento da semeadura, que foi realizada nos tubetes e nas bandejas, fixados em bancadas metálicas a $1 \mathrm{~m}$ da superfície. Foram colocadas três sementes por tubete ou célula, a uma profundidade de 1 a 2cm, conforme o tamanho destas.

As irrigações foram realizadas por um sistema de subirrigação por capilaridade, o qual se constituiu da imersão de 60 a $70 \%$ do volume dos tubetes ou das bandejas, a partir da base, em água, por um período de uma hora, duas vezes ao dia. Uma solução nutritiva com concentração de $4,0 \mathrm{~g} \mathrm{~L}^{-1}$ e uma relação entre os nutrientes de: N-1;P-0,14; K-0,34; Ca-1,41; e Mg-0,13 foi adicionada à água de irrigação a partir dos 60 dias após a semeadura (DAS). $\mathrm{O}$ pH da água de irrigação foi monitorado a cada reposição da solução nutritiva, mantendo-o na faixa de 5,5 a 6,0.

Aos 150 dias após a semeadura, determinouse o desenvolvimento vegetativo dos porta-enxertos por meio das seguintes avaliações: diâmetro do tronco em nível do colo, em mm; comprimento da parte aérea, medida do colo até o ápice do tronco, em cm; área foliar por plântula em $\mathrm{cm}^{2}$; área foliar por folha em $\mathrm{cm}^{2}$, medida por meio da passagem das folhas por um medidor de área foliar de marca LI-Cor, modelo LI - 3100; número de folhas por planta; fitomassas secas da raiz, da parte aérea e total (raiz + parte aérea), em gramas, obtidas 
pela secagem à estufa, com temperatura de $65^{\circ} \mathrm{C}$, até peso constante.

Para a variável altura da parte aérea, o experimento constituiu-se de um trifatorial, sendo testados dois tipos de recipientes na parcela principal, três porta-enxertos e quatro datas de avaliação (60, 90 , 120 e 150 dias após a semeadura) nas subparcelas. Nesse caso, foram utilizadas também 20 plantas por parcela e três repetições.

As médias foram submetidas à análise de variância e comparadas pelo teste de Duncan em nível de $5 \%$ de significância, enquanto a variável comprimento da parte aérea dos porta-enxertos, ao longo do tempo, foi submetida à análise de regressão polinomial, no programa SANEST.

\section{RESULTADOS E DISCUSSÃO}

O crescimento em altura, independentemente do porta-enxerto e do recipiente utilizado, mostrou-se lento até os 90DAS, a partir do qual sofreu uma aceleração até o final do experimento, como conseqüência do aumento da temperatura no decorrer do período (Figura 1). No início do experimento, as temperaturas médias estiveram abaixo dos $12^{\circ} \mathrm{C}$ aos 15DAS, a partir do qual se mantiveram na faixa dos $10^{\circ} \mathrm{C}$ (Figura 2). Abaixo dos $12^{\circ} \mathrm{C}$, o desenvolvimento vegetativo dos citros é reduzido, e a faixa ideal situa-se entre $20^{\circ} \mathrm{C}$ e $30^{\circ} \mathrm{C}$ (KOLLER, 2006). A época do ano em que a semeadura é realizada é um fator relevante na germinação de porta-enxertos de citros, embora a germinação ocorra na faixa de $12^{\circ} \mathrm{C}$ a $40^{\circ} \mathrm{C}$, o desenvolvimento é otimizado em temperatura de $26^{\circ} \mathrm{C}$ a $28^{\circ} \mathrm{C}$ (OLIVEIRA \& SCIVITTARO, 2007).

O comprimento da parte aérea, ao longo do tempo, foi semelhante para as plantas cultivadas em bandeja e tubetes até os 120DAS (Figura 1A). A partir desse período, as plantas produzidas em bandeja passaram a apresentar um incremento em torno de $10 \%$. Com relação aos porta-enxertos, o 'C37' apresentou um crescimento da parte aérea semelhante ao 'Trifoliata' e ambos os porta-enxertos foram superiores à tangerineira 'Sunki' em torno de 30\%, ao longo dos 150 dias de cultivo (Figura 1B).

Os porta-enxertos 'Trifoliata' e 'FEPAGRO C37' apresentaram altura final semelhante e significativamente maior que a altura da tangerineira 'Sunki'. O citrangeiro 'FEPAGRO C37' teve maior diâmetro ao nível e maior acúmulo de massa seca. Foi observado um comportamento semelhante de acúmulo de massa seca entre o 'Trifoliata' e a tangerineira 'Sunki'. (Tabela 1). O 'Trifoliata' apresentou o menor índice de área foliar por planta e por folha e um maior número de folhas por planta. O 'FEPAGRO C37' apresentou um índice de área foliar maior que o Trifoliata, mas inferior à tangerineira 'Sunki' (Tabela 1). Esses resultados em área foliar são considerados normais, devido às características intrínsecas da própria espécie, pois o ‘Trifoliata’ apresenta folhas pequenas, quando comparado a outros porta-enxertos cítricos (SCHÄFER, 2004). Os citrangeiros são híbridos entre Citrus sinensis [L.] Osbeck x Poncirus trifoliata e apresentam características semelhantes às do Trifoliata, como o porte reduzido, a tolerância ao frio e a indução de frutos de boa qualidade (SCHÄFER, 2004).

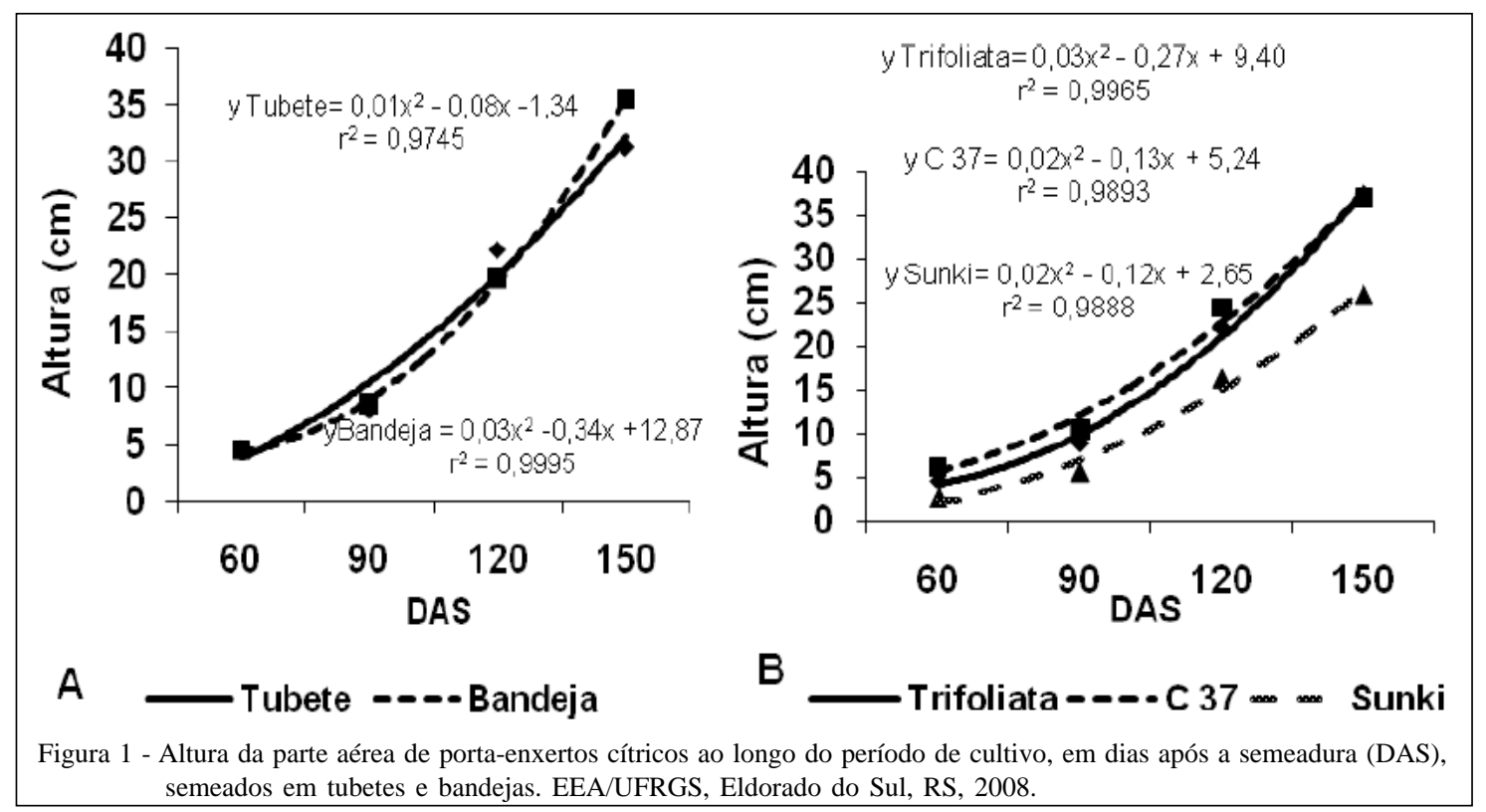

Ciência Rural, v.39, n.6, set, 2009. 


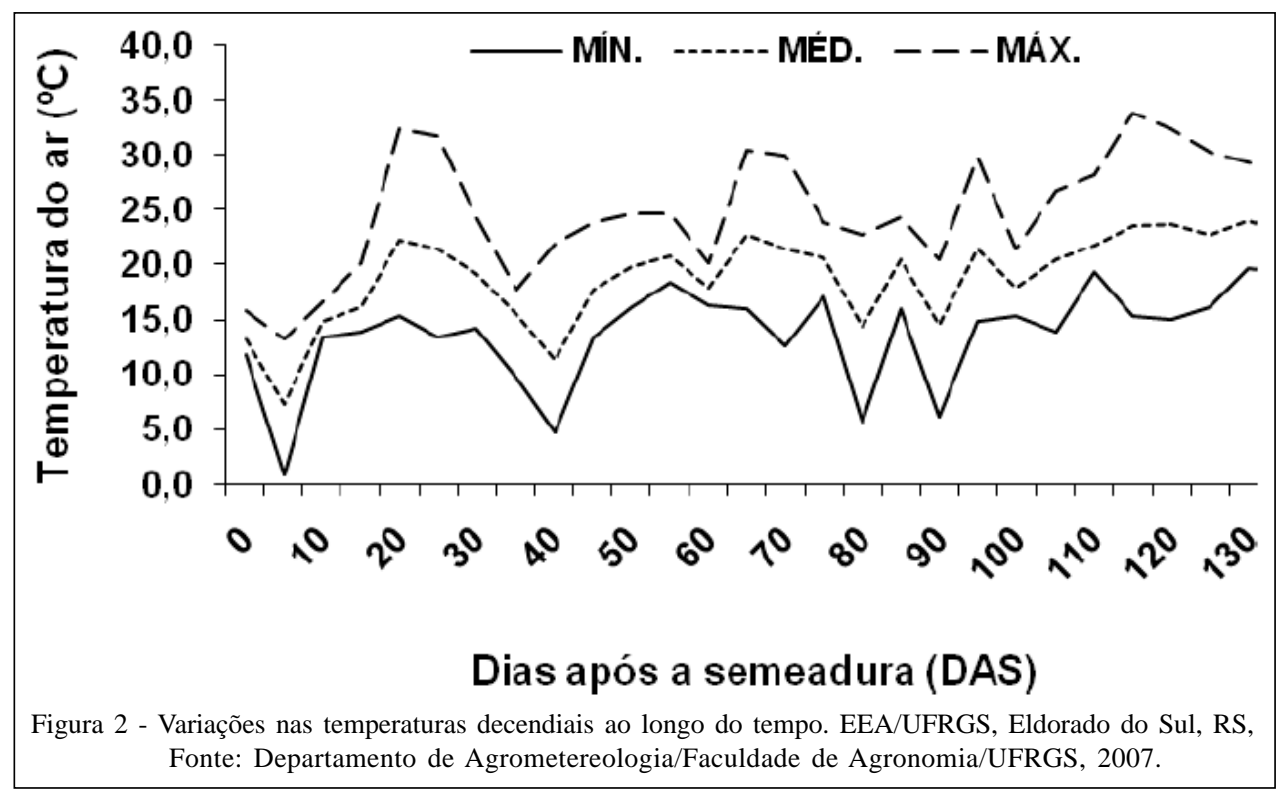

Em outro experimento, o limoeiro 'Cravo' mostrou-se superior em diâmetro à tangerineira 'Cleópatra'. Essa diferença é normal em razão das características de cada espécie, uma vez que o limoeiro 'Cravo' é conhecido por seu vigor, e a tangerineira 'Cleópatra' apresenta crescimento em altura e dificuldades de engrossamento do caule (JABUR \& MARTINS, 2002). A exemplo desses autores, a tangerineira 'Sunki', quando comparada com o citrangeiro 'FEPAGRO C37'e com o 'Trifoliata', apresenta crescimento menos vigoroso em altura e diâmetro da haste, apesar de maior área foliar.

Diferenças entre os porta-enxertos são comuns de serem encontradas, pelas características genéticas peculiares a cada porta-enxerto. (SCHÄFER, 2004). Esse autor, aos 120DAS, obteve alturas superiores a $15 \mathrm{~cm}$ para o 'Trifoliata' e 13 e $12 \mathrm{~cm}$ para os citrangeiros 'FEPAGRO C37' e 'FEPAGRO C13', respectivamente, e $10 \mathrm{~cm}$ para o limoeiro 'Cravo'. Os valores encontrados por esse autor para o diâmetro ao nível do colo foram similares entre os porta-enxertos, porém foram inferiores aos observados neste trabalho. Essa diferença em altura e diâmetro deve-se ao período de cultivo dos porta-enxertos, que, no presente trabalho, foi de 150 dias, possivelmente aliado ao manejo de adubação com fertirrigação contínua. Esse autor também observou diferenças em área foliar entre os porta-enxertos, o citrangeiro 'FEPAGRO C37' foi superior ao 'FEPAGRO C13', ao limoeiro ‘Cravo' e ao 'Trifoliata', que, por sua vez, teve o menor índice de área foliar, apesar de apresentar o maior número de folhas (SCHÄFER, 2004).
Os porta-enxertos semeados em bandejas alveoladas, comparados aos porta-enxertos semeados em tubetes, apresentaram um incremento em diâmetro em torno de $12 \%$, em área foliar por folha de 9,5\% e, em aérea foliar por planta, o incremento chegou a 23,5\% (Tabela 1). Quanto à altura final, não houve diferença significativa entre os recipientes utilizados. Os portaenxertos produzidos em bandejas mostraram também um incremento superior a 30\% no acúmulo de massa seca (Tabela 1).

A altura do recipiente é fundamental na determinação da água retida após a irrigação, pois, com o aumento da altura do recipiente, ocorre um aumento na capacidade de aeração. Porém, isso também provoca uma consequente diminuição na retenção de água devido ao aumento da drenagem e à ação da força gravitacional (BAILEY et al., 2005). Concomitantemente, o sistema de irrigação empregado influenciou os resultados, pois como se usou a subcapilaridade, em que a água é fornecida na parte inferior do substrato, umedecendo o substrato por força capilar, quanto mais alto o recipiente, mais dificuldade a água tem de irrigar as camadas superiores. Como os tubetes possuem uma altura superior em relação às bandejas $(140 \mathrm{~mm})$, as plantas semeadas em bandejas provavelmente desfrutaram de uma maior uniformidade na umidade do substrato, culminando em um maior crescimento do sistema radicular nas bandejas e, por conseguinte, da parte aérea dos porta-enxertos.

Foram alcançados resultados superiores em diâmetro e peso seco de raiz, folha e caule para plantas de limoeiro 'Cravo' oriundas do sistema de blocos prensados em comparação com plantas oriundas de

Ciência Rural, v.39, n.6, set, 2009. 
Tabela 1 - Características de crescimento dos porta-enxertos Poncirus trifoliata, citrangeiro 'C37' e tangerineira 'Sunki’ cultivados em diferentes recipientes, 150 dias após a semeadura. EEA/UFRGS, Eldorado do Sul, RS, 2008.

\begin{tabular}{|c|c|c|c|c|c|c|c|c|}
\hline \multirow{2}{*}{ Porta-enxertos } & \multirow{2}{*}{$\begin{array}{l}\text { Altura } \\
\text { (cm) }\end{array}$} & \multirow{2}{*}{$\begin{array}{c}\text { Diâmetro } \\
\text { (mm) }\end{array}$} & \multicolumn{2}{|c|}{-----Área Foliar $\left(\mathrm{cm}^{2}\right)$----- } & \multirow{2}{*}{$\begin{array}{l}\text { N. de } \\
\text { Folhas }\end{array}$} & \multicolumn{3}{|c|}{----------Massa Seca (g)----------- } \\
\hline & & & Folha & Planta & & Raiz & P.Aérea & Total \\
\hline 'Trifoliata' & $37,31 a^{1}$ & $2,23 b$ & $2,62 c$ & $51,26 c$ & $19,39 a$ & $0,25 b$ & $1,13 b$ & $1,38 b$ \\
\hline ‘C37’ & $36,84 a$ & $2,99 a$ & $6,21 b$ & $75,42 b$ & $12,14 b$ & $0,46 a$ & $1,84 \mathrm{a}$ & $2,30 a$ \\
\hline 'Sunki' & $25,97 b$ & $1,92 \mathrm{c}$ & $6,94 a$ & $117,38 a$ & $17,01 \mathrm{a}$ & $0,20 \mathrm{~b}$ & $1,00 \mathrm{~b}$ & $1,19 \mathrm{~b}$ \\
\hline CV(\%) & 16,6 & 5,0 & 8,0 & 11,6 & 15,4 & 22,2 & 13,2 & 14,6 \\
\hline \multicolumn{9}{|l|}{ Recipientes } \\
\hline Bandeja & 35,44 & $2,52 \mathrm{a}$ & $5,52 \mathrm{a}$ & $92,17 \mathrm{a}$ & $18,09 a$ & $0,36 \mathrm{a}$ & $1,57 \mathrm{a}$ & 1,93a \\
\hline Tubete & 31,30 & $2,25 b$ & $5,00 \mathrm{~b}$ & $70,53 b$ & $14,27 b$ & $0,24 b$ & $1,07 \mathrm{~b}$ & $1,31 b$ \\
\hline CV(\%) & 7,5 & 3,8 & 4,4 & 5,8 & 3,9 & 6,3 & 7,5 & 7,2 \\
\hline
\end{tabular}

${ }^{1}$ Médias seguidas por letras diferentes, na mesma coluna, diferem significativamente pelo teste de Duncan em nível de 5\% de probabilidade de erro.

tubetes (SERRANO et al., 2004). Outros resultados favoráveis ao desenvolvimento vegetativo de plantas oriundas de blocos prensados em relação a plantas produzidas em tubetes são descritos para outras espécies frutíferas, como a goiabeira (SCHIAVO \& MARTINS, 2002). As plantas produzidas em tubetes sofrem restrições no crescimento lateral das raízes impostas pelas paredes, as quais provocam deformações às raízes por direcionar seu crescimento para baixo, ao longo das paredes dos tubetes (LEAL et al., 2005). Quando o sistema radicial pivotante encontra a parte final do tubete, algumas anomalias morfológicas são desencadeadas, como o intumescimento da região apical e a ramificação das raízes, com posterior subdivisão do sistema radicial (BALDASSARI et al., 2003).

Assim, as raízes das plantas cultivadas nas células com formato piramidal das bandejas de isopor podem ter sido submetidas a menores restrições devido à ausência de estrias longitudinais e por estas apresentarem células mais largas que o diâmetro dos tubetes; portanto, as plantas cresceram com uma arquitetura radicular diferente. A confirmação dessa hipótese está na maior massa de raízes das plantas cultivadas nas bandejas e, como há uma relação direta entre desenvolvimento radicial e aéreo, houve também maior crescimento da parte aérea daquelas cultivadas nas bandejas.

\section{CONCLUSÕES}

Os porta-enxertos 'FEPAGRO C37' e 'Trifoliata' apresentaram um maior vigor inicial, comparativamente à tangerineira 'Sunki' . Ao empregarse o sistema de irrigação por sub-capilaridade, podem ser usados tubetes e bandejas de alvéolos de isopor, sendo mais indicado o segundo tipo, por acelerar o desenvolvimento dos porta-enxertos cítricos.

\section{AGRADECIMENTO}

À Coordenação de Aperfeiçoamento de Pessoal de Nível Superior (CAPES), pela Bolsa de Produtividade de Pesquisa do autor P. T. L. Teixeira

\section{REFERÊNCIAS}

BAILEY, D. A et al. Greenhouse substrates and fertilization. Raleigh: North Caroline State University, 2005. Capturado em 01 jun. 2005. On line. Disponível em: <http:// www.ces.ncsu.edu/depts/hort/floriculture/plugs/ghsubfert.pdf >

BALDASSARI, R.B. et al. Declínio dos citros: algo a ver com o sistema de produção de mudas cítricas. Revista Brasileira de Fruticultura, Jaboticabal, v.25, n.2, p.357-360, 2003. Disponível em: <http://www.scielo.br/scielo.php?script=sci_arttext\&pid=S010029452003000200047\&lng=pt\&nrm=iso\&tlng=pt $>$. Doi: $10.1590 /$ S0100-29452003000200047.

LEAL, P.L. et al. Crescimento de mudas micropropagadas de bananeira micorrizadas em diferentes recipientes. Revista Brasileira de Fruticultura, Jaboticabal, v.27, n.1, p.8487, 2005. Disponível em: <http://www.scielo.br/ scielo.php ? s c ri pt = sci_art text \& pid = S 0100 29452005000100023\&lng $=$ pt $\&$ nrm $=$ iso\&tlng=pt $>$. Doi: 10.1590/S0100-29452005000100023.

JABUR, M.A.; MARTINS, A.B.G. Influência de substratos na formação dos porta-enxertos: Limoeiro 'Cravo (Citrus limonia Osbeck) e Tangerineira 'Cleópatra' (Citrus reshni Hort. ex Tanaka). Revista Brasileira de Fruticultura, Jaboticabal, v.24, n.2, p.514-518, 2002. Disponível em: <http:// 
www.scielo.br/scielo.php?script=sci_arttext\&pid=S0100$29452002000200047 \& \operatorname{lng}=p t \& n r m=i$ so \& $\ln g=p t>$. Doi: 10.1590/S0100-29452002000200047.

KOLLER, O.C. Clima e solo In: KOLLER, O.C. (Coord.). Citricultura: 1. Laranja: tecnologia de produção, pós-colheita, industrialização e comercialização. Porto Alegre: Cinco Continentes, 2006. Cap.3, p.27-40.

OLIVEIRA, R.P. de; SCIVITTARO, W.B. Formação do portaenxerto Trifoliata: época de semeadura e tegumento na emergência de plântulas. Ciência Rural. Santa Maria. v.37, n.1, p.281-283, 2007. Disponível em: <http://www.scielo.br/ scielo.php? script =sci_arttext \& pid=S 0103 $84782007000100047 \& \operatorname{lng}=$ pt $\& n r m=i s o \& t \operatorname{lng}=p t>$. Doi: 10.1590/S0103-84782007000100047.

SCHÄFER, G. Produção de porta-enxertos cítricos em recipientes e ambiente protegido no Rio Grande do Sul. 2004. 129f. Tese (Doutorado em Fitotecnia) - Programa de Pós-graduação em Fitotecnia, Faculdade de Agronomia, Universidade Federal do Rio Grande do Sul, Porto Alegre, RS.
SCIVITTARO, W.B. et al. Adubação nitrogenada na formação de porta-enxertos de limoeiro 'Cravo' em tubetes. Revista Brasileira de Fruticultura, Jaboticabal, v.26, n.1, p.131135, 2004. Disponível em: <http://www.scielo.br/ scielo.php? script=sci_arttext \& pid=S 0100 $29452004000100036 \& \operatorname{lng}=$ pt $\&$ nrm $=$ iso $\&$ tlng $=$ pt $>$. Doi: 10.1590/S0100-29452004000100036.

SCHIAVO, J.A.; MARTINS, M.A. Produção de mudas de goiabeira (Psidium guajava L.), inoculados com o fungo micorrízico arbuscular Glomus clarum, em substrato agroindustrial. Revista Brasileira de Fruticultura, Jaboticabal, v.24, n.2, p.519-523, 2002. Disponível em: <http://www.scielo.br/scielo.php?script=sci_arttext\&pid=S010029452002000200048\&lng=pt\&nrm=iso\&tlng=pt $>$. Doi: 10.1590/ S0100-29452002000200048.

SERRANO, L.A.L. et al. Efeito de sistemas de produção e doses de adubo de liberação lenta no estado nutricional de porta-enxerto cítrico. Revista Brasileira de Fruticultura, Jaboticabal, v.26, n.3, p.524-528, 2004. Disponível em: <http://www.scielo.br/ scielo.php? script = sci_art text \& pid=S 0100 29452004000300036\&lng=pt\&nrm=iso\&tlng=pt $>$. Doi: 10.1590/ S0100-29452004000300036.

Ciência Rural, v.39, n.6, set, 2009. 